\title{
Helicobacter pylori infection and gastric carcinogenesis in animal models
}

\author{
Masae Tatematsu, Koji Nozaki, and Tetsuya Tsukamoto \\ Division of Oncological Pathology, Aichi Cancer Center Research Institute, 1-1 Kanokoden, Chikusa-ku, Nagoya, Aichi 464-8681, Japan
}

\begin{abstract}
The effects of Helicobacter pylori infection on gastric disorders have been proven by many epidemiological and experimental studies. To explore the relationships between $H$. pylori infection and gastric carcinogenesis, many factors, including host responses, environmental status, and the virulence factors of the bacteria should be taken into account. Mongolian gerbils (Meriones unguiculatus) can be easily infected with $\boldsymbol{H}$. pylori, and provide an excellent in-vivo experimental model to clarify the role of $\boldsymbol{H}$. pylori in active gastritis, peptic ulcers, intestinal metaplasia, and gastric carcinoma. Studies have revealed that $H$. pylori infection markedly enhances all histological types of gastric cancers in gerbils treated with a chemical carcinogen. Eradication reduced the enhancing effect of $\boldsymbol{H}$. pylori on gastric carcinogenesis, whereas a high-salt diet synergistically enhanced the effect of $H$. pylori. Various factors involving inflammation, cell proliferation, and cell differentiation could be examined with this experimental model to help elucidate this mechanisms of gastric carcinogenesis.
\end{abstract}

Key word Helicobacter pylori · Gastric cancer · Animal model $\cdot$ Mongolian gerbil $\cdot$ Eradication

\section{Introduction}

The role of Helicobacter pylori infection in gastric disorders has been well demonstrated. A positive relationship between $H$. pylori infection and gastric cancers has also been confirmed serologically in humans. However, it is also well known that only a small population of $H$. pylori-infected people develop gastric cancers. To find whether all $H$. pylori strains really act as carcinogens, and to determine whether $H$. pylori should be eradicated in all $H$. pylori-infected patients so as to prevent

Offprint requests to: $\mathrm{M}$. Tatematsu

Received: October 23, 2002 / Accepted: December 9, 2002 gastric cancers, much more evidence should be accumulated, including the variation of virulence factors in the bacteria, host responses to inflammation, side-effects after eradication, and the putative drug-resistance of the bacteria induced by incomplete eradication. Recently, many experimental studies regarding the relationships between $H$. pylori infection and gastric carcinogenesis have presented new findings. In this review article, we review reports providing basic data on $H$. pylori infection and gastric carcinogenesis.

\section{H. pylori infection and gastric carcinoma in humans}

Warren and Marshall [1] succeeded in detecting a gramnegative bacillus in human gastric mucosa in 1983. Marshal himself [2] proved the gastritis after self-ingestion with the bacteria. Parsonnet et al. [3], Nomura et al. [4], and Forman et al. [5] conducted prospective studies showing higher anti-H. pylori titers in patients with gastric cancer than in controls in 1991. In 1993 the EUROGAST Study Group demonstrated that a high prevalence of $H$. pylori correlated with a high incidence of gastric cancers [6], and WHO/International Agency for Research on Cancer (IARC) concluded that $H$. pylori was a definite group 1 carcinogen in 1994 [7]. Huang et al. [8] demonstrated, in a metaanalysis, the relationship between $H$. pylori seropositivity and gastric cancer.

Graham et al. [9] revealed that eradication of $H$. pylori resulted in the healing of gastric ulcers, and the longterm prospective study of Kuipers et al. [10] showed that $H$. pylori infection correlated with gastritis and intestinal metaplasia. Asaka et al. [11] found that H. pylori-seropositive patients developed intestinal metaplasia and atrophic gastritis with aging, while seronogative people did not, proving a strong correlation between $H$. pylori infection and atrophic gastritis, rather than aging. 
The high prevalence of $H$. pylori infection in the Japanese population has hidden the difference in $H$. pylori seropositivity between cancer-bearing people and controls. However, Kikuchi et al. [12] demonstrated a higher odds ratio of gastric carcinogenesis in H. pyloriseropositive young Japanese, showing that poorly differentiated carcinomas also had a close relationship with $H$. pylori infection. Uemura et al. [13] proved that patients with atrophic gastritis, intestinal metaplasia, gastric ulcers, or hyperplastic polyps had a high risk for gastric carcinogenesis, while patients with duodenal ulcers did not. Correa et al. [14] studied the possibility of chemoprevention of gastric dysplasia in a randomized trial of antioxidant supplements and anti-H. pylori therapy.

\section{H. pylori-infected animal models}

Many kinds of animal models have been employed to examine the effect of $H$. pylori infection on gastric disorders. In $H$. pylori-infected gnotobiotic piglets, submucosal edema, increased gastric mucus production, and the progressive development of mucosal lymphoid follicles was observed [15]. Similarly, in the H. pyloricolonized stomachs of gnotobiotic dogs, gastric lesions, showing lymphoplasmacytic infiltration with follicle formation and infiltration of neutrophils and eosinophils in the lamina propria were induced [16].

Some primates, including cynomolgus monkeys [17], rhesus monkeys [18], and Japanese monkeys [19], were also employed for experimental studies. In a study using Japanese monkeys, long infection with $H$. pylori resulted in atrophic gastritis, and eradication of $H$. pylori was effective in reducing inflammation [20]. No intestinal metaplasia or carcinoma was induced in this study of longterm infection. The gastric lesions were similar to those in humans; however, the longterm observation period and the specialized breeding facilities needed are considered to present some barrier to detailed studies using these primates as experimental animals.

A spiral-shaped bacterium, closely related to $H$. pylori, isolated from the cat stomach, and named "Helicobacter felis" made it possible to investigate small animal models of gastric infection. Mice infected with $H$. felis showed acute inflammatory responses with eosinophils and neutrophils and lymphocytes, and large lymphoid nodules in the submucosa [21]. In a study using six different strains of mice, $H$. pylori-infected $\mathrm{C} 3 \mathrm{H} / \mathrm{He}$ mice showed moderate colonization of the antrum with little development of atrophy, while $H$. pylori-infected C57BL/6 mice showed excellent colonization of the antrum at 2 months. However, 6 months after infection, there was moderate to severe atrophy associated with a loss of bacteria from the antrum [22].
A study using $H$. felis-infected BALB/c mice demonstrated lymphoid infiltrate lesions with morphology closely resembling that of human gastric mucosaassociated lymphoid tissue (MALT)oma [23].

Lee et al. [24] established the Sydney strain of H. pylori (strain SS1) from clinical isolates, with high levels of consistent colonization especially achieved in C57BL/6 mice. The bacterium attached firmly to the gastric epithelium, and chronic active gastritis slowly developed that progressed to severe atrophy. A guineapig model of chronic gastric infection with the Sydney strain of $H$. pylori had multifocal, mild-to-moderate lymphohistiocytic antral gastritis and formation of antral lymphoid follicles [25].

Concerning gastric carcinogenesis, a study with negative findings has been reported using $H$. pyloriinfected C57BL/6 mice [26]. H. pylori has urease activity and produces ammonia in the human stomach, and an enhancing effect of ammonia on gastric carcinogenesis was demonstrated in $N$-methyl- $N^{\prime}$-nitro- $N$ nitrosoguanidine ( $\mathrm{MNNG}$ )-treated rats, while ammonia itself did not initiate carcinogenesis [27]. The development of pepsinogen-altered pyloric glands (PAPG), preneoplastic lesions of the glandular stomach, was promoted by $H$. pylori infection in the glandular stomachs of $N$-methyl- $N$-nitrosourea (MNU)-pretreated BALB/c mice [28].

\section{H. pylori-infected Mongolian gerbil model}

In 1996, Hirayama et al. [29] reported the induction of gastric ulcer and intestinal metaplasia in Mongolian gerbils infected with $H$. pylori. Mongolian gerbils can be consistently infected with $H$. pylori, and the resultant chronic active gastritis, peptic ulcers, and intestinal metaplasia resemble lesions apparent in humans. Thus, they can be ideal experimental model animals for detailed analysis of the role of $H$. pylori in gastric disorders [29]. After infection with $H$. pylori, the glandular stomachs of Mongolian gerbils show hyperplastic changes, erosion, varying degrees of multifocal cystic dilatation, infiltration of inflammatory cells, and proliferation of the gastric glands into submucosa with interruptions of the lamina muscularis mucosa, forming dysplastic lesions called "heterotopic proliferative glands (HPG)". These submucosal lesions, surrounded with collagen fibers, show a phenotypic shift from gastric-type to intestinal-type with the appearance of Paneth cells during the overall course of $H$. pylori infection. Eradication of $H$. pylori resulted in reduced gastric lesions, partial interruption of the lamina muscularis mucosa, and regenerative changes seen as evidence of former injury [30]. In studies exploring gastric carcinogenesis employing Mongolian gerbils [31-35], no carci- 
noma with obvious cellular atypia was observed in the H. pylori-solely-infected group. However, Watanabe et al. [36], and Honda et al. [37] concluded that H. pylori infection alone could induce well-differentiated adenocarcinomas, at very high incidences (38\% [36] and 40\% [37]), in the glandular stomachs of gerbils at week 62 or week 72, whereas Hirayama et al. [38] found that $H$. pylori infection induced only one poorly differentiated adenocarcinoma at week $64(1.8 \%)$. The incidences and histological patterns of the lesions differed greatly in these three studies. One possible reason for this discrepancy is the difference in the diagnosis of submucosal lesions and well-differentiated adenocarcinomas in this animal species. Further more detailed investigations of the characteristics of neoplasms in this animal model would provide a much clearer idea of the relationship between $H$. pylori infection and gastric carcinogenesis.

\section{H. pylori-infected and carcinogen-treated Mongolian gerbil model: modification of gastric carcinogenesis}

To assess the putative causal link between $H$. pylori infection and carcinogenesis in the glandular stomach, gerbils were treated with a combination of chemical carcinogens and $H$. pylori infection. The animals were able to tolerate a 30-ppm exposure to MNU or 400-ppm exposure to MNNG treatment ad libitum. As a result, all histological types of stomach cancer development were induced due to exposure to carcinogens [31]. The variety of histological types of gastric cancers, similar to those in humans, implies the advantage of using this animal model in experimental studies of gastric carcinogenesis (Figs. 1 and 2).
A combination of 3-30 ppm of MNU administration and infection with $\mathrm{H}$. pylori strain ATCC43504 resulted in a $5.0 \%-36.8 \%$ incidence of carcinogenesis after 40 weeks of observation [32]. Moreover, the combination of 20-300 ppm of MNNG administration and infection with $H$. pylori resulted in a $14.8 \%-60.0 \%$ incidence of carcinogenesis after 50 weeks of observation [33]. H. pylori infection apparently enhances all histological types of gastric carcinogenesis and its progression in gerbils treated with chemical carcinogens [34]. Further, the administration of $30 \mathrm{ppm}$ of $\mathrm{MNU}$ and infection with $H$. pylori induced a $65.2 \%$ incidence of carcinogenesis at week 50, while the same condition plus eradication resulted in a $20.8 \%$ incidence of carcinogenesis. Also, H. pylori infection and the administration of $10 \mathrm{ppm}$ of MNU induced a carcinogenesis incidence of $34.6 \%$, while the same condition plus eradication resulted in a $9.1 \%$ incidence. Thus, the enhancing effect of $H$. pylori infection in gastric carcinogenesis due to a chemical carcinogen was diminished by subsequent eradication [35]. The timing of MNU administration affects the histological types of gastric carcinogenesis in gerbils infected with $H$. pylori [39]. Another study reported well-differentiated adenocarcinomas in 50\%$66.7 \%$ of animals treated with $50 \mathrm{ppm}$ of MNNG and infection with $H$. pylori at weeks 24-52 [40].

A high-salt diet is also a risk factor in gastric carcinogenesis. High salt administration significantly enhanced gastric carcinogenesis in MNNG-treated rats [41]. A cross-sectional study conducted in humans revealed an association between the prevalence of $H$. pylori and the frequent intake of salty food in Japan [42]. H. pylori can infect the stomachs of gerbils persistently. The organism preferentially colonizes and forms microcolonies within

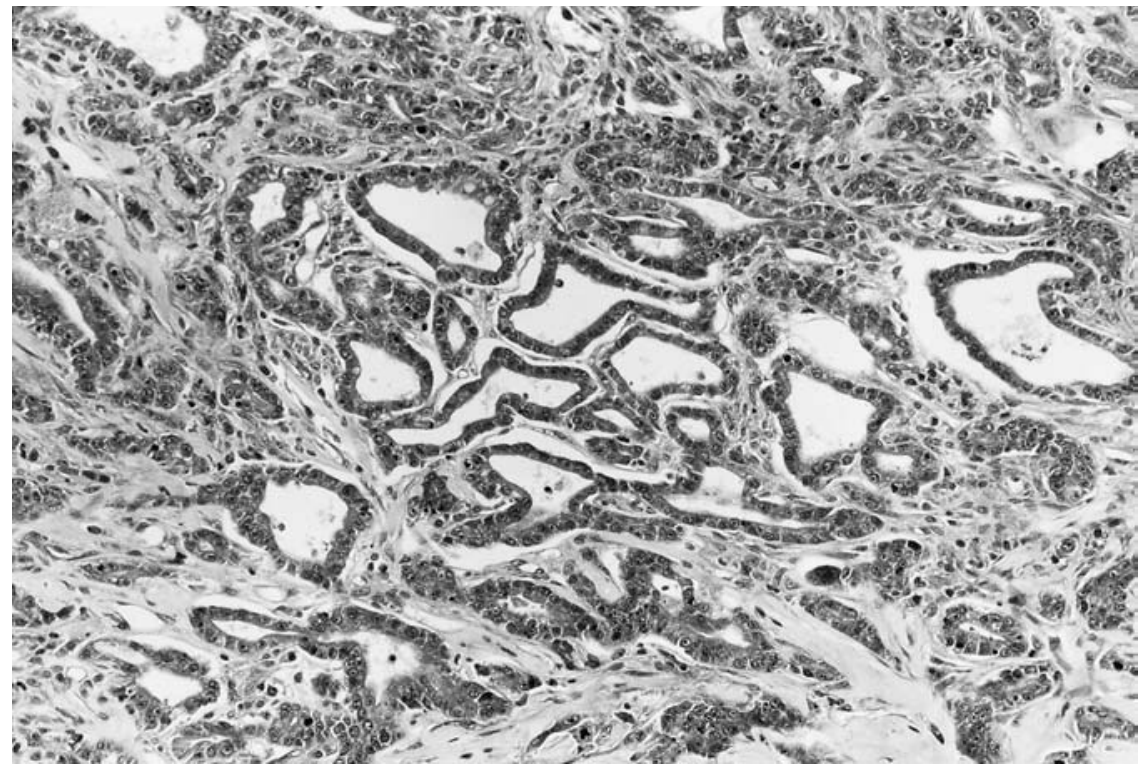

Fig. 1. Well- to moderately differentiated adenocarcinoma. $\mathrm{H} \& \mathrm{E}, \times 50$ 


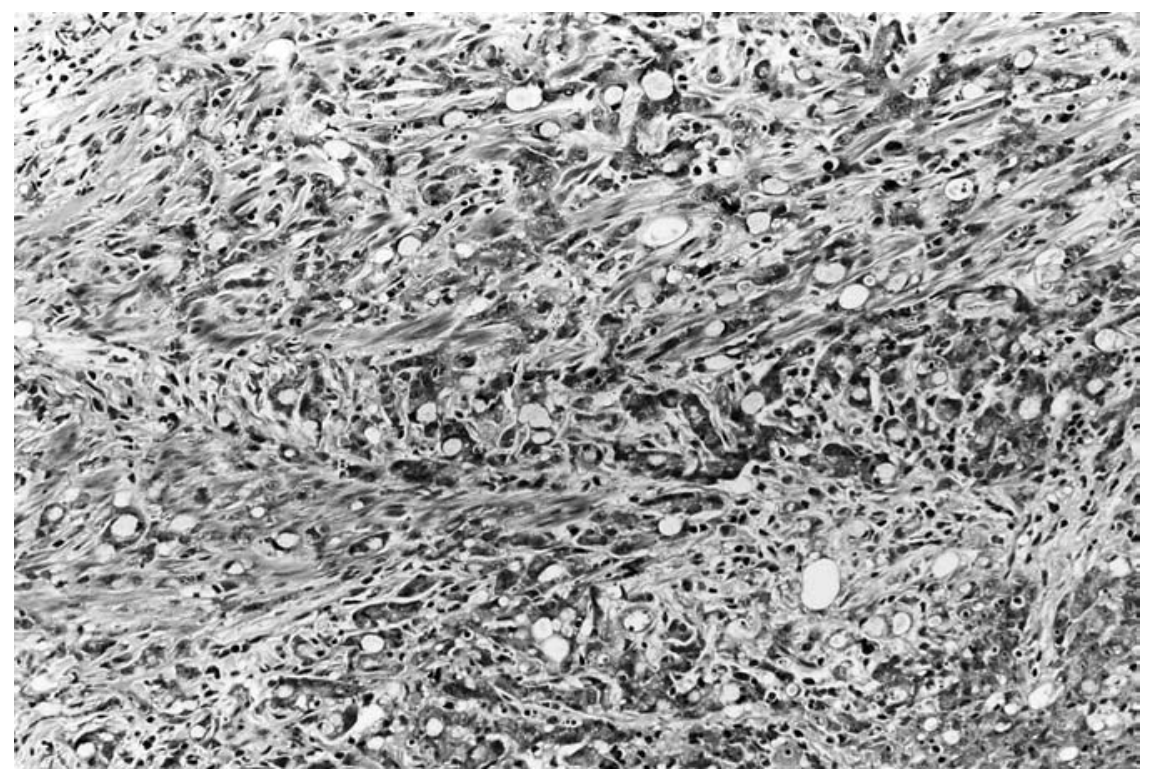

Fig. 2. Poorly differentiated adenocarcinoma. $\mathrm{H} \& \mathrm{E}, \times 50$ the mucous gel layer of surface mucous-cell-type mucins in the human stomach [43]. Mucins from gland mucous cells may disturb the movement of $H$. pylori within the mucous gel layer [44]. The mucous layer of the stomach will be damaged by high salt administration, and the lowered mucosal defense caused by the high-salt diet might serve to enhance the risk of exposure to carcinogens existing in the glandular stomach. Fox et al. [45] demonstrated that a high-salt diet enhanced $H$. pylori colonization in C57BL/6 mice. In a recent study using Mongolian gerbils, the incidence of adenocarcinomas was highest in the group treated with $20 \mathrm{ppm}$ of MNU, H. pylori infection, and a $10 \%$ highsalt diet (32.1\%). A high-salt diet enhanced the effects of $H$. pylori infection on gastric carcinogenesis, and the two factors, H. pylori infection and the high-salt diet, acted synergistically to promote the development of stomach cancers [46]. The gastric mucosa contains several kinds of acid mucopolysaccharides. The presence of a high $\mathrm{NaCl}$ concentration decreases the viscosity of the gastric mucus, reduces the protective mucous barrier, similarly to the effects of surface-active agents, and allows direct contact of carcinogens with the gastric mucosa [41]. H. pylori infection has, in fact, been shown to exacerbate stomach mucosal damage due to MNU or a salty diet in mice [45].

H. pylori infection during childhood might also present a high risk for gastric carcinogenesis. To evaluate the difference in susceptibility to stomach carcinogenesis among various ages at which $H$. pylori infection was acquired, the following experiment was performed. Gerbils were infected with $H$. pylori at different ages $(4,18$, or 32 weeks) and then treated with MNU in the same period. At 52 weeks, the incidences of adenocarcinoma in the early (4-week), middle (18-week), or late (32-week) $H$. pylori-infected groups were $60 \%, 18.4 \%$, and $10 \%$, respectively. Higher titers of serum IgG for $H$. pylori and higher gastrin levels were seen in the early-infected animals. The early acquisition of $H$. pylori increased the risk for gastric carcinogenesis, in relation to host immunologic responses [47].

\section{H. pylori infection and host responses}

H. pylori produces ammonia from urea in the host stomach with urease, neutralizes the gastric acid, and multiplies in the neutralized mucin layer of the host stomach [43]. Activation of the phagocyte oxidative metabolism by $H$. pylori [48], alterations in gastric juice ascorbic acid concentrations in $\mathrm{H}$. pylori-seropositive patients [49], and increased expression of inducible nitric oxide synthase and peroxynitrite induced by $H$. $p y$ lori [50] have been demonstrated.

Crabtree et al. [51] reported that interleukin (IL)-8 expression was higher in $H$. pylori-infected gastric mucosa than in normal gastric mucosa. The HLA-DQ type of the host plays a role in the severity of atrophic gastritis in $H$. pylori-seropositive patients [52], and ElOmar et al. [53,54] demonstrated an association between IL-1 polymorphisms and an increased risk of gastric cancer. Smoking habit affected this relationship [55], and a synergistic interaction between IL-1B and IL-1RN polymorphisms and the risk of gastric cancer was also demonstrated [56]. H. pylori activates nuclear factor kappa $\mathrm{B}(\mathrm{NF}-\mathrm{\kappa B})$ through a signaling pathway 
involving I $\mathrm{B}$ B kinases in gastric cancer cells [57], and the role of $H$. pylori-activated cyclin D1 gene expression through the mitogen-activated protein kinase (MAPK) pathway in gastric cancer cells was also demonstrated [58]. Complete genome sequences of multiple $H$. pylori strains are now available $[59,60]$, and the proteinprotein interaction map of $H$. pylori was built through a yeast two-hybrid assay [61]. Further, it has been shown that the H. pylori virulence factor CagA, translocated from the bacteria into gastric epithelial cells, can be tyrosine-phosphorylated in the host epithelial cells [62], and it can perturb signal transduction by physically interacting with a host cell protein, SHP-2, that connects receptor tyrosine kinases and ras [63].

Studies have demonstrated the indubitable relationship between $H$. pylori infection and gastric disorders. The pathogenic roles of $H$. pylori in vivo still remain unsolved, and further experimental studies concerning the formation of gastric cell proliferation and enhancement of gastric cancers are needed. Many factors underlying the inflammation, cell proliferation, and biological mediators observed after $H$. pylori infection can be examined, using appropriate experimental animal models, to help elucidate the mechanisms of gastric carcinogenesis and, possibly, to help provide a firm basis for human cancer prevention.

Acknowledgments We thank Dr. Toshiko Kumagai, Central Clinical Laboratories, Shinshu University Hospital; Dr. Atsushi Sugiyama, First Department of Surgery, Shinshu University; Professor Tsutomu Katsuyama, Department of Laboratory Medicine, Shinshu University School of Medicine; and Dr. Nobuyuki Shimizu and Professor Michio Kaminishi, Department of Gastrointestinal Surgery, Postgraduate School of Medicine, The University of Tokyo.

\section{References}

1. Warren JR, Marshall BJ. Unidentified curved bacilli on gastric epithelium in active gastritis. Lancet 1983;I:1273-5.

2. Marshall BJ, Armstrong JA, McGechie DB, Glancy RJ. Attempt to fulfill Koch's postulates for pyloric Campylobacter. Med J Aust 1985;142:436-9.

3. Parsonnet J, Friedman GD, Vandersteen DP, Chang Y, Vogelman JH, Orentreich N, et al. Helicobacter pylori infection and the risk of gastric carcinoma. N Engl J Med 1991;325:1127-31.

4. Nomura A, Stemmermann GN, Chyou PH, Kato I, Perez-Perez GI, Blaser MJ. Helicobacter pylori infection and gastric carcinoma among Japanese Americans in Hawaii. N Engl J Med 1991;325:1132-6.

5. Forman D, Newell DG, Fullerton F, Yarnell JW, Stacey AR, Wald N, et al. Association between infection with Helicobacter pylori and risk of gastric cancer: evidence from a prospective investigation. BMJ 1991;302:1302-5.

6. The EUROGAST Study Group. An international association between Helicobacter pylori infection and gastric cancer. Lancet 1993;341:1359-62.
7. IARC Working Group on the Evaluation of Carcinogenic Risks to Humans. Schistosomes, liver flukes and Helicobacter pylori. IARC Monogr Eval Carcinog Risks Hum 1994;61:1-241.

8. Huang JQ, Sridhar S, Chen Y, Hunt RH. Meta-analysis of the relationship between Helicobacter pylori seropositivity and gastric cancer. Gastroenterology 1998;114;1169-79.

9. Graham DY, Lew GM, Klein PD, Evans DG, Evans DJ Jr, Saeed ZA, et al. Effect of treatment of Helicobacter pylori infection on the long-term recurrence of gastric or duodenal ulcer. A randomized, controlled study. Ann Intern Med 1992;116:705-8.

10. Kuipers EJ, Uyterlinde AM, Pena AS, Roosendaal R, Pals G, Nelis GF, et al. Long-term sequelae of Helicobacter pylori gastritis. Lancet 1995;345:1525-8.

11. Asaka M, Kato M, Kudo M, Katagiri M, Nishikawa K, Koshiyama $\mathrm{H}$, et al. Atrophic changes of gastric mucosa are caused by Helicobacter pylori infection rather than aging: studies in asymptomatic Japanese adults. Helicobacter 1996;1:52-6.

12. Kikuchi S, Wada O, Nakajima T, Nishi T, Kobayashi O, Konishi $\mathrm{T}$, et al. Serum anti-Helicobacter pylori antibody and gastric carcinoma among young adults. Research Group on Prevention of Gastric Carcinoma among Young Adults. Cancer 1995;75: 2789-93.

13. Uemura N, Okamoto S, Yamamoto S, Matsumura N, Yamaguchi $\mathrm{S}$, Yamakido M, et al. Helicobacter pylori infection and the development of gastric cancer. N Engl J Med 2001;345:784-9.

14. Correa P, Fontham ET, Bravo JC, Bravo LE, Ruiz B, Zarama G, et al. Chemoprevention of gastric dysplasia: randomized trial of antioxidant supplements and anti-Helicobacter pylori therapy. J Natl Cancer Inst 2000;92:1881-8.

15. Krakowka S, Morgan DR, Kraft WG, Leunk RD. Establishment of gastric Campylobacter pylori infection in the neonatal gnotobiotic piglet. Infect Immun 1987;55:2789-96.

16. Radin MJ, Eaton KA, Krakowka S, Morgan DR, Lee A, Otto G, et al. Helicobacter pylori gastric infection in gnotobiotic beagle dogs. Infect Immun 1990;58:2606-12.

17. Takahashi S, Igarashi $\mathrm{H}$, Ishiyama N, Nakano M, Ozaki M, Ito M, et al. Serial change of gastric mucosa after challenging with Helicobacter pylori in the cynomolgus monkey. Zentralbl Bakteriol 1993;280:51-7.

18. Euler AR, Zurenko GE, Moe JB, Ulrich RG, Yagi Y. Evaluation of two monkey species (Macaca mulatta and Macaca fascicularis) as possible models for human Helicobacter pylori disease. J Clin Microbiol 1990;28:2285-90.

19. Shuto R, Fujioka T, Kubota T, Nasu M. Experimental gastritis induced by Helicobacter pylori in Japanese monkeys. Infect Immun 1993;61:933-9.

20. Fujioka T, Kubota T, Shuto R, Kodama R, Murakami K, Perparim K, et al. Establishment of an animal model for chronic gastritis with Helicobacter pylori: potential model for long-term observations. Eur J Gastroenterol Hepatol 1994;6(Suppl 1): S73-8.

21. Lee A, Fox JG, Otto G, Murphy JA. Small animal model of human Helicobacter pylori active chronic gastritis. Gastroenterology 1990;99:1315-23.

22. Sakagami T, Dixon M, O'Rourke J, Howlett R, Alderuccio F, Vella J, et al. Atrophic gastric changes in both Helicobacter felis and Helicobacter pylori infected mice are host dependent and separate from antral gastritis. Gut 1996;39:639-48.

23. Enno A, O'Rourke JL, Howlett CR, Jack A, Dixon MF, Lee A. MALToma-like lesions in the murine gastric mucosa after long-term infection with Helicobacter felis. A mouse model of Helicobacter pylori-induced gastric lymphoma. Am J Pathol 1995; 147:217-22.

24. Lee A, O'Rourke J, De Ungria MC, Robertson B, Daskalopoulos G, Dixon MF. A standardized mouse model of Helicobacter pylori infection: introducing the Sydney strain. Gastroenterology 1997; 112:1386-97.

25. Shomer NH, Dangler CA, Whary MT, Fox JG. Experimental Helicobacter pylori infection induces antral gastritis and gastric 
mucosa-associated lymphoid tissue in guinea pigs. Infect Immun 1998;66:2614-8.

26. Nakamura Y, Sakagami T, Yamamoto N, Yokota Y, Koizuka H, Hori K, et al. Helicobacter pylori does not promote $N$-methyl- $N$ nitrosourea-induced gastric carcinogenesis in SPF C57BL/6 mice. Jpn J Cancer Res 2002;93:111-6.

27. Tsujii M, Kawano S, Tsuji S, Nagano K, Ito T, Hayashi N, et al. Ammonia: a possible promoter in Helicobacter pylori-related gastric carcinogenesis. Cancer Lett 1992;65:15-8.

28. Shimizu N, Kaminishi M, Tatematsu M, Tsuji E, Yoshikawa A, Yamaguchi $\mathrm{H}$, et al. Helicobacter pylori promotes development of pepsinogen-altered pyloric glands, a preneoplastic lesion of glandular stomach of BALB/c mice pretreated with $N$-methyl- $N$ nitrosourea. Cancer Lett 1998;123:63-9.

29. Hirayama F, Takagi S, Kusuhara H, Iwao E, Yokoyama Y, Ikeda Y. Induction of gastric ulcer and intestinal metaplasia in Mongolian gerbils infected with Helicobacter pylori. J Gastroenterol 1996;31:755-7.

30. Nozaki K, Shimizu N, Tsukamoto T, Inada K, Cao X, Ikehara Y, et al. Reversibility of heterotopic proliferative glands in glandular stomach of Helicobacter pylori-infected Mongolian gerbils on eradication. Jpn J Cancer Res 2002;93:374-81.

31. Tatematsu M, Yamamoto M, Shimizu N, Yoshikawa A, Fukami H, Kaminishi M, et al. Induction of glandular stomach cancers in Helicobacter pylori-sensitive Mongolian gerbils treated with $N$-methyl- $N$-nitrosourea and $N$-methyl- $N^{\prime}$-nitro- $N$ nitrosoguanidine in drinking water. Jpn J Cancer Res 1998;89:97104.

32. Sugiyama A, Maruta F, Ikeno $\mathrm{T}$, Ishida $\mathrm{K}$, Kawasaki $\mathrm{S}$, Katsuyama T, et al. Helicobacter pylori infection enhances $N$ methyl- $N$-nitrosourea-induced stomach carcinogenesis in the Mongolian gerbil. Cancer Res 1998;58:2067-9.

33. Shimizu N, Inada K, Nakanishi H, Tsukamoto T, Ikehara Y, Kaminishi M, et al. Helicobacter pylori infection enhances glandular stomach carcinogenesis in Mongolian gerbils treated with chemical carcinogens. Carcinogenesis 1999;20:66976.

34. Shimizu N, Inada KI, Tsukamoto T, Nakanishi H, Ikehara Y, Yoshikawa A, et al. New animal model of glandular stomach carcinogenesis in Mongolian gerbils infected with Helicobacter pylori and treated with a chemical carcinogen. J Gastroenterol 1999;34(Suppl 11):61-6.

35. Shimizu N, Ikehara $Y$, Inada $K$, Nakanishi $H$, Tsukamoto T, Nozaki K, et al. Eradication diminishes enhancing effects of Helicobacter pylori infection on glandular stomach carcinogenesis in Mongolian gerbils. Cancer Res 2000;60:1512-4.

36. Watanabe T, Tada M, Nagai H, Sasaki S, Nakao M. Helicobacter pylori infection induces gastric cancer in Mongolian gerbils. Gastroenterology 1998;115:642-8.

37. Honda S, Fujioka T, Tokieda M, Satoh R, Nishizono A, Nasu M. Development of Helicobacter pylori-induced gastric carcinoma in Mongolian gerbils. Cancer Res 1998;58:4255-9.

38. Hirayama F, Takagi S, Iwao E, Yokoyama Y, Haga K, Hanada S. Development of poorly differentiated adenocarcinoma and carcinoid due to long-term Helicobacter pylori colonization in Mongolian gerbils. J Gastroenterol 1999;34:545-6.

39. Maruta F, Sugiyama A, Ishida K, Ikeno T, Murakami M, Kawasaki S, et al. Timing of $N$-methyl- $N$-nitrosourea administration affects gastric carcinogenesis in Mongolian gerbils infected with Helicobacter pylori. Cancer Lett 2000;160:99-105.

40. Tokieda M, Honda S, Fujioka T, Nasu M. Effect of Helicobacter pylori infection on the $N$-methyl- $N^{\prime}$-nitro- $N$-nitrosoguanidineinduced gastric carcinogenesis in Mongolian gerbils. Carcinogenesis 1999;20:1261-6.

41. Tatematsu M, Takahashi M, Fukushima S, Hananouchi M, Shirai T. Effects in rats of sodium chloride on experimental gastric cancers induced by $N$-methyl- $N^{\prime}$-nitro- $N$-nitrosoguanidine or 4-nitroquinoline-1-oxide. J Natl Cancer Inst 1975;55:1016.
42. Tsugane S, Tei Y, Takahashi T, Watanabe S, Sugano K. Salty food intake and risk of Helicobacter pylori infection. Jpn J Cancer Res 1994;85:474-8.

43. Shimizu T, Akamatsu T, Sugiyama A, Ota H, Katsuyama T. Helicobacter pylori and the surface mucous gel layer of the human stomach. Helicobacter 1996;1:207-18.

44. Hidaka E, Ota H, Hidaka H, Hayama M, Matsuzawa K, Akamatsu T, et al. Helicobacter pylori and two ultrastructurally distinct layers of gastric mucous cell mucins in the surface mucous gel layer. Gut 2001;49:474-80.

45. Fox JG, Dangler CA, Taylor NS, King A, Koh TJ, Wang TC. High-salt diet induces gastric epithelial hyperplasia and parietal cell loss, and enhances Helicobacter pylori colonization in C57BL/ 6 mice. Cancer Res 1999;1:4823-8.

46. Nozaki K, Shimizu N, Inada K, Tsukamoto T, Inoue M, Kumagai $\mathrm{T}$, et al. Synergistic promoting effects of Helicobacter pylori infection and high-salt diet on gastric carcinogenesis in Mongolian gerbils. Jpn J Cancer Res 2002;93:1083-9.

47. Cao X, Tsukamoto T, Nozaki K, Tanaka H, Shimizu N, Kaminishi $\mathrm{M}$, et al. Earlier Helicobacter pylori-infection increases the risk for the $N$-methyl- $N$-nitrosourea induced stomach carcinogenesis in Mongolian gerbils. Jpn J Cancer Res 2002;93:1293-8.

48. Nielsen H, Andersen LP. Activation of human phagocyte oxidative metabolism by Helicobacter pylori. Gastroenterology 1992; 103:1747-53.

49. Sobala GM, Schorah CJ, Pignatelli B, Crabtree JE, Martin IG, Scott N, et al. High gastric juice ascorbic acid concentrations in members of a gastric cancer family. Carcinogenesis 1993;14:291-2.

50. Sakaguchi AA, Miura S, Takeuchi T, Hokari R, Mizumori M, Yoshida $\mathrm{H}$, et al. Increased expression of inducible nitric oxide synthase and peroxynitrite in Helicobacter pylori gastric ulcer. Free Radic Biol Med 1999;27:781-9.

51. Crabtree JE, Wyatt JI, Trejdosiewicz LK, Peichl P, Nichols PH, Ramsay N, et al. Interleukin-8 expression in Helicobacter pyloriinfected, normal, and neoplastic gastroduodenal mucosa. J Clin Pathol 1994;47:61-6.

52. Beales IL, Davey NJ, Pusey CD, Lechler RI, Calam J. Longterm sequelae of Helicobacter pylori gastritis. Lancet 1995;346: $381-2$.

53. El-Omar EM, Carrington M, Chow WH, McColl KE, Bream JH, Young HA, et al. Interleukin-1 polymorphisms associated with increased risk of gastric cancer. Nature 2000;404:398402.

54. El-Omar EM, Carrington M, Chow WH, McColl KE, Bream JH, Young HA, et al. The role of interleukin-1 polymorphisms in the pathogenesis of gastric cancer. Nature 2001;412:99.

55. Hamajima N, Katsuda N, Matsuo K, Saito T, Ito LS, Ando M, et al. Smoking habit and interleukin IB C-31T polymorphism. J Epidemiol 2001;11:120-5.

56. Machado JC, Pharoah P, Sousa S, Carvalho R, Oliveira C, Figueiredo $\mathrm{C}$, et al. Interleukin $1 \mathrm{~B}$ and interleukin $1 \mathrm{RN}$ polymorphisms are associated with increased risk of gastric carcinoma. Gastroenterology 2001;121:823-9.

57. Maeda S, Yoshida H, Ogura K, Mitsuno Y, Hirata Y, Yamaji Y, et al. H. pylori activates NF-kappaB through a signaling pathway involving IkappaB kinases, NF-kappaB-inducing kinase, TRAF2, and TRAF6 in gastric cancer cells. Gastroenterology 2000;119:97108.

58. Hirata Y, Maeda S, Mitsuno Y, Akanuma M, Yamaji Y, Ogura K, et al. Helicobacter pylori activates the cyclin D1 gene through mitogen-activated protein kinase pathway in gastric cancer cells. Infect Immun 2001;69:3965-71.

59. Tomb JF, White O, Kerlavage AR, Clayton RA, Sutton GG, Fleischmann RD, et al. The complete genome sequence of the gastric pathogen Helicobacter pylori. Nature 1997;388:539-47.

60. Alm RA, Ling LS, Moir DT, King BL, Brown ED, Doig PC, et al. Genomic-sequence comparison of two unrelated isolates of the human gastric pathogen Helicobacter pylori. Nature 1999;397: 176-80. 
61. Rain JC, Selig L, De Reuse H, Battaglia V, Reverdy C, Simon S, et al. The protein-protein interaction map of Helicobacter pylori. Nature 2001;409:211-5.

62. Asahi M, Azuma T, Ito S, Ito Y, Suto H, Nagai Y, et al. Helicobacter pylori CagA protein can be tyrosine phos- phorylated in gastric epithelial cells. J Exp Med 2000;191:593602.

63. Higashi H, Tsutsumi R, Muto S, Sugiyama T, Azuma T, Asaka M, et al. SHP-2 tyrosine phosphatase as an intracellular target of Helicobacter pylori CagA protein. Science 2002;25:683-6. 